\title{
Efficacy and Safety of Dexmedetomidine during Anesthesia Induction of Patients with Intracranial Tumor: A Preliminary Observational Trial
}

\author{
Jiangbei Cao, Wenzhu Shi, Weidong Mi, Hong Zhang* \\ Department of Anesthesiology and Operation Center, PLA General Hospital, Beijing, China. \\ Email: cjb2000@sina.com, *mazuimao301@yahoo.com.cn
}

Received September $15^{\text {th }}, 2013$; revised October $16^{\text {th }}, 2013$; accepted October $25^{\text {th }}, 2013$

Copyright (C) 2013 Jiangbei Cao et al. This is an open access article distributed under the Creative Commons Attribution License, which permits unrestricted use, distribution, and reproduction in any medium, provided the original work is properly cited.

\begin{abstract}
Background: The efficacy and safety of dexmedetomidine during the anesthesia induction of intracranial tumor patients remain unknown. We wondered whether loading infusion of dexmedetomidine $1 \mu \mathrm{g} / \mathrm{kg}$ over $10 \mathrm{~min}$ to intracranial tumor patients was as efficient and safe as to those abdominal disease patients. Methods: Patients aged $18-60$ years, male or female, ASA I or II, scheduled for intracranial tumor resection (Group N, $\mathrm{n}=30$ ) or abdominal operation (Group A, $\mathrm{n}=30$ ) were enrolled in this observational trial. Dexmedetomidine was administrated with a loading dosage of $1 \mu \mathrm{g} / \mathrm{kg}$ over $10 \mathrm{~min}$ following with continuous infusing of $0.5 \mu \mathrm{g} / \mathrm{kg} / \mathrm{h}$. Fentanyl, propofol and rocuronium were sequentially administered for anesthesia induction. Heart rate (HR), blood pressure (BP), pulse oxygen saturation $\left(\mathrm{SpO}_{2}\right)$, bispectral index (BIS) and other adverse effects were recorded from the beginning of loading infusion of dexmedetomidine to the end of endotracheal intubation. Results: Among with loading infusion, HR and BIS value decreased and were significantly lower at the end of infusion than before infusion $(P<0.01)$, but BP did not $(P>0.05)$. One patient of Group N dropped out from this trial because of a serious headache. 14 of 29 patients during dexmedetomidine loading infusion suffered hypoxemia $\left(\mathrm{SpO}_{2}<90 \%\right)$ in Group N, which was higher than 6 of 30 of in Group A $(P<0.05)$. No other side effects were recorded. Conclusion: A loading dosage of $1 \mu \mathrm{g} / \mathrm{kg}$ of dexmedetomidine was not suitable for the anesthesia induction of intracranial tumor patients as compared to patients undergoing abdominal operation.
\end{abstract}

Keywords: Dexmedetomidine; Intracranial Tumor; Adverse Effects; Loading Infusion

\section{Introduction}

Dexmedetomidine, a highly selective $\alpha_{2}$-adrenoreceptor agonist, is widely used as a sedative or an adjuvant agent for anesthesia induction and maintenance [1-6]. Patients sedated with dexmedetomidine could well tolerate the endotracheal intubation. When using as sedative, dexmedetomidine can increase hemodynamic stability, cause little respiratory depression and allow a rapid recovery $[1,7,8]$.

Preliminary data of the perioperative usage of dexmedetomidine in patients undergoing neurosurgery have indicated that preoperative usage of dexmedetomidine may spare opioid requirements and offer more stable hemodynamics during neurosurgery [9-11]. Besides dex-

\footnotetext{
*Corresponding author.
}

medetomidine's well-proven sedative effects, an increasing body of both in vitro and in vivo evidence indicates that dexmedetomidine also exerts a cell-protective effect on nervous tissue under ischemic conditions [12$15]$.

In addition, laryngoscopy and endotracheal intubation are apt to result in hypertension, tachycardia and arrhythmias, which is hazardous to those patients undergoing neurosurgery for brain tumor $[16,17]$. Therefore, it seems that dexmedetomidine used as an adjunct of anesthesia induction may be helpful to those patients undergoing neurosurgery. Dexmedetomidine loading infusion with the dosage of $1 \mu \mathrm{g} / \mathrm{kg}$ over $10 \mathrm{~min}$ showed its efficacy and safety to several kinds of operation patients [18-20]. However, the efficacy and safety of dexmedetomidine loading infusion during anesthesia induction to 
those intracranial tumor patients remain unknown. The objective of this preliminary observational trial was to investigate into the sedative effects, respiration inhibition, hemodynamic changes and adverse effects of dexmedetomidine with a loading infusion dosage $1 \mu \mathrm{g} / \mathrm{kg}$ over 10 min during introduction in neurosurgery patients.

\section{Patients and Methods}

This trial protocol was approved by the Ethics Committee of the General Hospital of PLA, Beijing, China. The written informed consents were obtained from all patients.

Sixty patients, male or female, aged 18 - 60 years, with American Society of Anesthesiologists (ASA) physical status I or II, were enrolled from April 2011 to October 2011 in this trial. Among these patients, 30 patients were scheduled to intracranial tumor resection (Group N), and the other 30 patients were scheduled for abdominal operation (Group A). The exclusion criteria included: patients with hepatic or renal insufficiency, a history of allergy to $\alpha_{2}$-adrenoreceptor agonist, a psychiatric or neuromuscular disorder, or predicted difficult airway.

All the patients were premeditated with intramuscular atropine of $0.5 \mathrm{mg}$ at $30 \mathrm{~min}$ before operation. After entering the operation room, patients were inserted intravenously catheter with a 20 - or 22 -gauge in a peripheral vein. The patients were first administered with a loading dosage of $1 \mu \mathrm{g} / \mathrm{kg}$ of dexmedetomidine $(200 \mu \mathrm{g} / \mathrm{ml}$, diluted with normal saline to $4 \mu \mathrm{g} / \mathrm{ml}$ ) over $10 \mathrm{~min}$ by a computer controlled pump infuser then followed to infuse with the rate of $0.5 \mu \mathrm{g} / \mathrm{kg} / \mathrm{h}$. When loading infusion was ended, fentanyl $2 \mu \mathrm{g} / \mathrm{kg}$, propofol $2 \mathrm{mg} / \mathrm{kg}$ and rocuronium $0.9 \mathrm{mg} / \mathrm{kg}$ were sequentially administered within $1 \mathrm{~min}$. Three minutes later, endotracheal intubation was performed by one of the two appointed attending anesthesiologists. Propofol and isoflurane were used for anesthesia maintenance.

Heart rate (HR), blood pressure (systolic and diastolic blood pressure, SBP and DBP), bispectral index (BIS) and pulse oxygen saturation $\left(\mathrm{SpO}_{2}\right)$ were recorded at the following time points: before dexmedetomidine loading infusion (T1), at the end of loading infusion (T2), before, during and 5 min after endotracheal intubation (T3-5, respectively).

Normally, during the period of loading infusion, the patients inhaled room air without extra-oxygen supplying. If a patient's $\mathrm{HR}<45 \mathrm{bpm}$ for $>3 \mathrm{~min}, \mathrm{SBP}<80 \mathrm{mmHg}$ for $>3 \mathrm{~min}$, or $\mathrm{SpO}_{2}<90 \%$ for $>1 \mathrm{~min}$, he (she) will drop out from this trial and then atropine, ephedrine or $100 \%$ oxygen via mask will be given [21]. The occurrence of adverse reactions including nausea and dry mouth were also noted.

\section{Statistical Analysis}

Data are presented as means \pm SD or proportion. Statistical analysis was performed using the SPSS 17.0 software for Windows (Chicago, IL). Proportion was compared using chi-square test. Age, weight and height were compared using independent-samples $t$ tests. HR, SBP, DBP, BIS and $\mathrm{SpO}_{2}$ were analyzed by using analysis of variance for repeated measurements. $P<0.05$ was considered to be statistically significant.

\section{Result}

All the surgeries were successfully completed. One patient from Group $\mathrm{N}$ was ceased to continue infusing dexmedetomidine because a severe headache occurred during the loading infusion. There was no significant difference with respect to demographic data between the two groups (Table 1).

As shown in Figure 1, the HR of Group $\mathrm{N}$ is faster than that of Group A ( $83 \pm 11$ bpm vs. $75 \pm 10$ bpm, $P<$ $0.01)$ before anesthesia. After loading infusion of dexmedetomidine at dosage of $1 \mu \mathrm{g} / \mathrm{kg}$, HR decreased significantly in both groups (the average HR of Group N was $62 \mathrm{bpm}$ and Group A was $61 \mathrm{bpm}$ independently, $P$ $<0.01$, compared with T1, Figure 1). However, there was no significant change in blood pressure during loading infusion or even during endotracheal intubation (Figure 2).

Among with the infusion of dexmedetomidine, the patient could be sedated effectively. After loading infusion, it showed that patients were deep sedated (the average BIS value decreased from 94 to 74 in Group N, from 95 to 76 in Group A, $P<0.01$, Figure 3). In this trial, we designed that all patients were limited to inhale room air during dexmedetomidine loading infusion. The results showed that at the end of loading infusion $\mathrm{SpO}_{2}$ value decreased from $98 \%$ to $95 \%$ of Group N and from $99 \%$ to $96 \%$ respectively $(P<0.01)$ (Figure 4). Though no patient was dropped off in case of $\mathrm{SpO}_{2}$ lower than $90 \%$ for more than 1 minute. However, it happened to some patients of both groups that their $\mathrm{SpO}_{2}$ value were fluctuating between $86 \%-96 \%$. Among them, 14 of 29 patients in Group N while 6 of 30 patients in Group A whose $\mathrm{SpO}_{2}$ value dropped below $90 \%$ at least once during dexmedetomidine loading infusion $(P<0.05)$.

Table 1. Demographics in the two groups.

\begin{tabular}{ccc}
\hline Characteristic & Group N & Group A \\
\hline Sex, male/female & $15 / 15$ & $14 / 16$ \\
Age, mean (SD), yr & $44(11)$ & $45(12)$ \\
Weight, mean (SD), kg & $63(10)$ & $62(8)$ \\
Height, mean (SD), cm & $165(9)$ & $164(7)$ \\
\hline
\end{tabular}




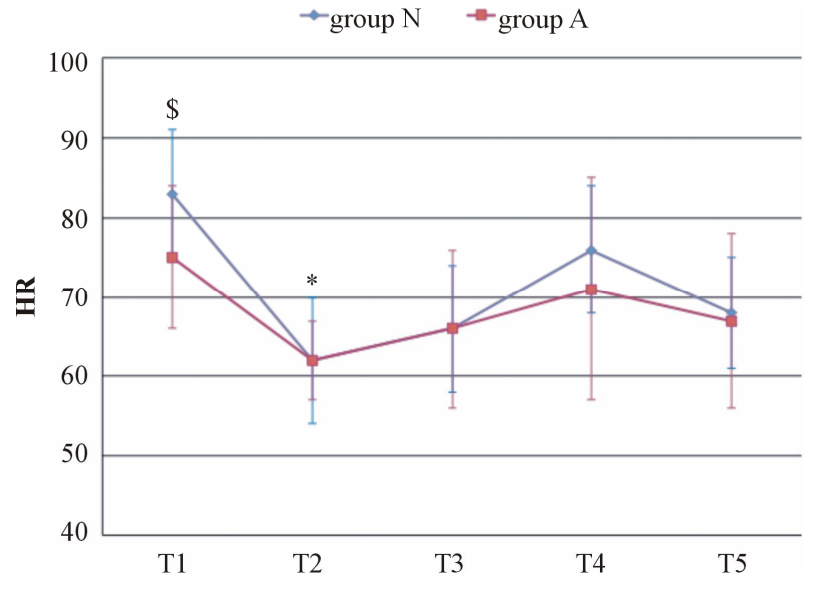

Figure 1. Changes of HR during dexmedetomidine loading infusion and endotracheal intubation of patients underwent neurosurgery or abdomen operation. $\chi \pm s, n=29$ in Group $\mathbf{N}, \mathbf{n}=30$ in Group A. compared with Group A, ${ }^{\$} P<\mathbf{0 . 0 1}$; Compared with $\mathrm{T} 1,{ }^{*} P<0.01$. T1, before dexmedetomidine loading infusion; $T 2$, at the end of dexmedetomidine loading infusion; T3-5, before, during and $5 \mathrm{~min}$ after endotracheal intubation.

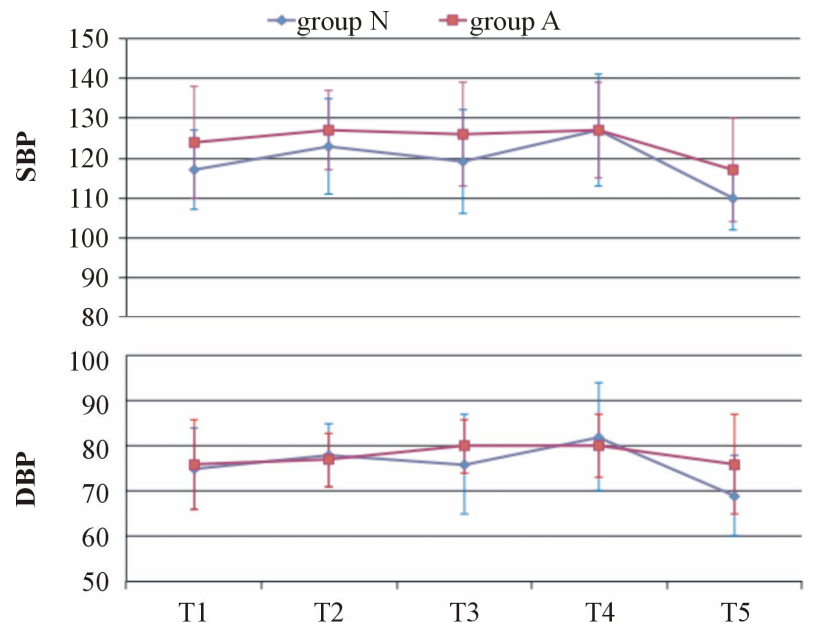

Figure 2. Changes of SBP and DBP during dexmedetomidine loading infusion and endotracheal intubation of patients underwent neurosurgery or abdomen operation. $\chi \pm \mathrm{s}$, $\mathbf{n}=\mathbf{2 9}$ in Group $\mathbf{N}, \mathbf{n}=30$ in Group A. The SBP and DBP changed within $20 \%$ of base line (T1), and there were no significant difference compared with $\mathrm{T} 1$. T1, before dexmedetomidine loading infusion; $\mathrm{T} 2$, at the end of dexmedetomidine loading infusion; T3-5, before, during and 5 min after endotracheal intubation.

There was no patient complained of the common adverse reactions in both groups, for example nausea or dry mouth. However, an 18-year-old male patient with pituitary tumor was dropped out from this trial because he suffered a serious headache after dexmedetomidine loading infusing for about $5 \mathrm{~min}$. His headache disappeared within $2 \mathrm{~min}$ after the stop of dexmedetomidine

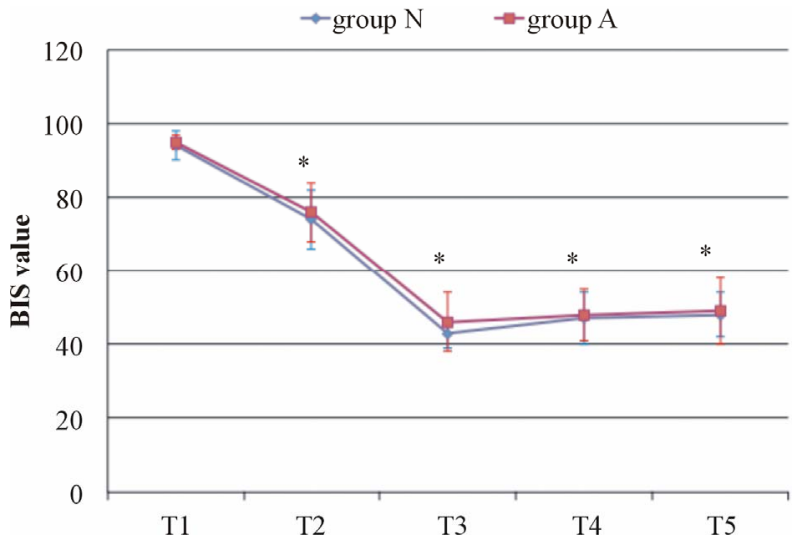

Figure 3. Changes of BIS during dexmedetomidine loading infusion and endotracheal intubation of patients underwent neurosurgery or abdomen operation. $\chi \pm \mathbf{s}, \mathbf{n}=29$ in Group $\mathbf{N}, \mathbf{n}=30$ in Group A. compared with $\mathrm{T} 1,{ }^{*} \boldsymbol{P}<0.01$. T1, before dexmedetomidine loading infusion; $\mathrm{T} 2$, at the end of dexmedetomidine loading infusion; T3-5, before, during and $5 \mathrm{~min}$ after endotracheal intubation.

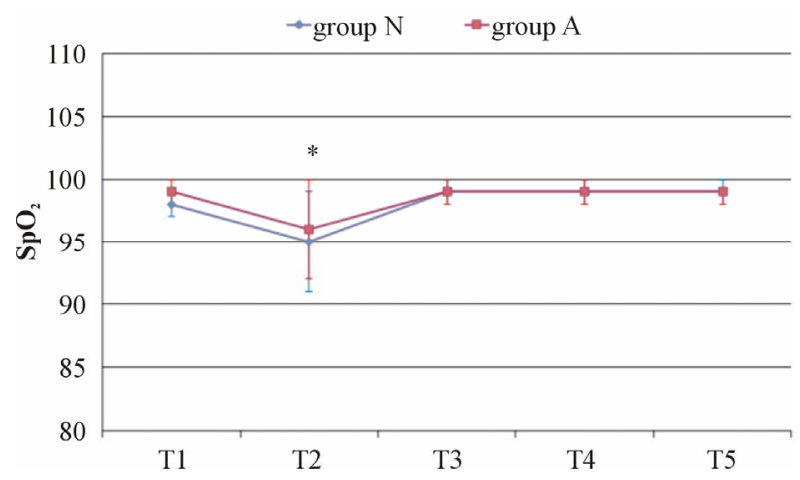

Figure 4. Changes of $\mathrm{SpO}_{2}$ during dexmedetomidine loading infusion and endotracheal intubation of patients underwent craniotomy or abdomen operation. $\chi \pm \mathrm{s}, \mathrm{n}=29$ in Group N, $\mathbf{n}=30$ in Group A. compared with T1, ${ }^{*} \boldsymbol{P}<\mathbf{0 . 0 1}$. $\mathrm{T} 1$, before the dexmedetomidine loading infusion; $\mathrm{T} 2$, at the end of dexmedetomidine loading infusion; T3-5, before, during and $5 \mathrm{~min}$ after endotracheal intubation.

infusing. In this episode, his SBP increased from 138 to $158 \mathrm{mmHg}$ when headache occurred, and returned to 141 mmHg when headache disappeared.

\section{Discussion}

In this trial, we compared the efficacy of dexemdetomidine in a method of commonly used $[22,23]$ between neurosurgery and abdominal operation patients. The results showed that $\mathrm{BP}, \mathrm{SpO}_{2}$ and $\mathrm{BIS}$ had no significantly statistical difference between the two groups. However, during loading infusing of dexmedetomidine with 1 $\mu \mathrm{g} / \mathrm{kg}$ over $10 \mathrm{~min}$, the intracranial tumor patients had a higher incidence of hypoxemia $\left(\mathrm{SpO}_{2}<90 \%\right)$ than those abdominal operation patients, and also dexmedetomidine 
might induce serious headache in patients with intracranial tumor.

Dexmedetomidine as an $\alpha_{2}$-adrenoceptor agonist is widely used for the sedation of intubated and mechanically ventilated patients in the intensive care setting, as well as for the sedation of non-intubated patients before and during surgical procedures $[7,24,25]$. In addition to its sedative properties, dexmedetomidine causes sympatholysis and decreases anesthetic requirements, which may decrease opioid use and make it attractive for use as an adjunct to general anesthesia. Moreover, the neuroprotective property of dexmedetomidine has been demonstrated in various animal models of cerebral ischemia $[9,26]$. Drummond and colleagues [27] recently demonstrated a simultaneous decrease of $\mathrm{CBF}$ and $\mathrm{CMRO}_{2}$ with dexmedetomidine in healthy volunteers. However, the cerebral blood flow (CBF)/cerebral metabolic rate (CMR) ratio did not decrease and suggest that $\mathrm{CMR}-\mathrm{CBF}$ coupling is preserved during dexmedetomidine administration. Also, researchers found that dexmedetomidine could decrease the adrenergic response to the trauma of surgery and improve perioperative hemodynamic stability [28]. All these documents show that pretreatment or loading infusion with dexmedetomidine before induction has the advantage to those neurosurgery patients.

However, there are few researches on the safety of using dexmedetomidine to intracranial tumor patients and which dosage should be used as an adjunct to anesthesia induction, though it was recommended that dexmedetomidine $1 \mu \mathrm{g} / \mathrm{kg}$ as loading infusion over $10 \mathrm{~min}$ was a common clinical dosage [22]. In this study, we designed a trial to investigate the safety and efficiency of dexmedetomidine usage to those intracranial patients who received a loading infusion dosage of $1 \mu \mathrm{g} / \mathrm{kg}$ over 10 $\min$ as an adjunct to anesthesia induction. Additionally, patients were allowed to inhale room air but not the $100 \% \mathrm{O}_{2}$ during loading infusion during this trial to investigate the dexmedetomidine' effect on patients' respiration function.

The primary composite endpoint of this study was defined as patients having any of the following during loading infusion period: 1) $\mathrm{HR}<45 \mathrm{bpm}$ for $>3$ minutes, 2) systolic blood pressure (SBP) $<80 \mathrm{mmHg}$ for $>3$ minutes, 3) or $\mathrm{SpO}_{2}<90 \%$ for $>1$ min, or 4) administration of vasoactive agents (including $<500 \mu \mathrm{g}$ phenylephrine by bolus or infusion, any epinephrine) or any atropine. It was found that the HR of almost all the patients including intracranial tumor patients and abdominal operation patients decreased obviously. The HR of some patients was less than $50 \mathrm{bpm}$ (but haven't match the deadline of $45 \mathrm{bpm}$ for more than $3 \mathrm{~min}$ ) during dexmedetomidine loading infusion. In our study, the base HR of intracranial tumor patients was faster significantly than abdominal operation patients. It may be due to different treatments of diseases before operation. However, HR was almost the same of both groups at the end of dexmedetomidine loading infusion. In addition, the hemodynamic frustration changed slightly during dexmedetomidine infusion and even during endotracheal intubation.

It is of very important for patients to keep normal central respiratory rhythm during sedation or introduction of anesthesia. Dexmedetomidine, an $\alpha_{2}$-adrenergic agonist, causes an unique kind of sedation, acting on the subcortical areas, which resembles natural sleep without respiratory depression [29]. The monitoring of BIS value in our study showed that during dexmedetomidine loading infusion, patients could be sedated and reached a level of deep sleep gradually (the BIS of both group at the end of loading infusion $<76,0=$ no cortical activity, or coma; $40-60=$ unconscious; $70-90=$ varying levels of conscious sedation; 100 -fully awake). During loading infusion, patients could be still breathing almost normally. It was shown that $\mathrm{SpO}_{2}$ could always keep beyond $90 \%$ when patients inhaling room air but not $100 \%$ oxygen. However, during dexmedetomidine loading infusion, some patients' $\mathrm{SpO}_{2}$ decreased and fluctuated in a wide range between $86 \%$ and $96 \%$. And the results could tell us that the incidence of hypoxemia (the $\mathrm{SpO}_{2}$ was dropped below $90 \%$ at least one time) was much higher in those patients with intracranial tumor than those patients undergoing abdominal operation. In other words, our data implied that dexemdetomidine might lead to more serious respiration depression in patients with intracranial tumor. The reason why the incidence of hypoxemia was much higher in intracranial tumor patients than in abdominal patients may be due to the ICP changes of intracranial tumor patients, but still remains unclear.

Dexmedetomidine has been used in over one million patients since its approval in 1999 [30]. The most frequently reported adverse reactions of dexmetomidine usage were hypotension, nausea, and bradycardia [31-33]. In this study, during dexmedetomidine loading infusion, there was a young man suffered an unpredictable headache. The exact reason for headache happening was far to know, but the occurrence of headache warning us to notice this adverse reaction when dexemdetomidine used in clinics, particularly in patients with intracranial tumor. Sometimes, a higher loading infusion doses may be required to ensure adequate sedation. However, a higher dose of dexmedetomidine can have a higher incidence of hypertension, bradycardia, and hypotension [7,34,35]. Patients with intracranial tumor showed less endurance than those patients without intracranial tumor.

The main limitation of our study was the small sample 
size. The sample size was too small especially when observing adverse reactions. Therefore, further large sample size investigations are needed in the near future to determine the safety of dexemdetomidine in neurosurgery. Further studies are necessary to establish an optimal dosage regimen especially for patients underwent craniotomy, because those patients maybe always endure a high ICP and experience an unexpected adverse reaction. Secondly, we had not checked the precise sedation scores of patients and also had not recorded the frequent of respiration. Therefore, further investigations maybe need to answer these questions.

\section{Conclusion}

Compared with those without intracranial tumor patients, dexemdetomidine with a loading dosage $1 \mu \mathrm{g} / \mathrm{kg}$ may induce more serious respiration depression and sometimes headache in intracranial tumor patients. And further investigations with a large sample size are needed to determine the safety rang of dexemdetomidine in intracranial tumor patients.

\section{Acknowledgements}

We thank Dr. Jianjun Yang for reviewing this manuscript.

\section{REFERENCES}

[1] R. Siddappa, J. Riggins, S. Kariyanna, P. Calkins and A. T. Rotta, "High-Dose Dexmedetomidine Sedation for Pediatric MRI," Pediatric Anesthesia, Vol. 21, No. 2, 2011, pp. 153-158.

http://dx.doi.org/10.1111/j.1460-9592.2010.03502.x

[2] S. Strom, "Preoperative Evaluation, Premedication, and Induction of Anesthesia in Infants and Children," Current Opinion in Anesthesiology, Vol. 25, No. 3, 2012, pp. 321325. http://dx.doi.org/10.1097/ACO.0b013e3283530e0d

[3] A. Akin, A. Bayram, A. Esmaoglu, Z. Tosun, R. Aksu, R. Altuntas and A. Boyaci, "Dexmedetomidine vs Midazolam for Premedication of Pediatric Patients Undergoing Anesthesia," Pediatric Anesthesia, Vol. 22, No. 9, 2012, pp. 871-876.

http://dx.doi.org/10.1111/j.1460-9592.2012.03802.x

[4] A. Patel, M. Davidson, M. C. Tran, H. Quraishi, C. Schoenberg, M. Sant, A. Lin and X. Sun, "Dexmedetomidine Infusion for Analgesia and Prevention of Emergence Agitation in Children with Obstructive Sleep Apnea Syndrome Undergoing Tonsillectomy and Adenoidectomy," Anesthesia \& Analgesia, Vol. 111, No. 4, 2010, pp. 1004-1010.

[5] N. Ohtani, K. Kida, K. Shoji, Y. Yasui and E. Masaki, "Recovery Profiles from Dexmedetomidine as a General Anesthetic Adjuvant in Patients Undergoing Lower Abdominal Surgery," Anesthesia \& Analgesia, Vol. 107, No. 6, 2008, pp. 1871-1874.

\section{http://dx.doi.org/10.1213/ane.0b013e3181887fcc}

[6] K. Kida, N. Ohtani, K. Shoji, Y. Yasui and E. Masaki, "Postoperative Pain Status after Intraoperative Systemic Dexmedetomidine and Epidural Neostigmine in Patients Undergoing Lower Abdominal Surgery," European Journal of Anaesthesiology, Vol. 25, No. 11, 2008, pp. 869875. http://dx.doi.org/10.1017/S0265021508004493

[7] K. P. Mason, D. Zurakowski, S. Zgleszewski, R. Prescilla, P. J. Fontaine and J. A. Dinardo, "Incidence and Predictors of Hypertension during High-Dose Dexmedetomidine Sedation for Pediatric MRI," Pediatric Anesthesia, Vol. 20, No. 6, 2010, pp. 516-523. http://dx.doi.org/10.1111/j.1460-9592.2010.03299.x

[8] J. W. Berkenbosch, P. C. Wankum and J. D. Tobias, "Prospective Evaluation of Dexmedetomidine for Noninvasive Procedural Sedation in Children," Pediatric Critical Care Medicine, Vol. 6, No. 4, 2005, pp. 435-439. http://dx.doi.org/10.1097/01.PCC.0000163680.50087.93

[9] K. Sato, T. Kimura, T. Nishikawa, Y. Tobe and Y. Masaki, "Neuroprotective Effects of a Combination of Dexmedetomidine and Hypothermia after Incomplete Cerebral Ischemia in Rats," Acta Anaesthesiologica Scandinavica, Vol. 54, No. 3, 2010, pp. 377-382. http://dx.doi.org/10.1111/j.1399-6576.2009.02139.x

[10] N. E. Ngwenyama, J. Anderson, D. G. Hoernschemeyer and J. D. Tobias, "Effects of Dexmedetomidine on Propofol and Remifentanil Infusion Rates during Total Intravenous Anesthesia for Spine Surgery in Adolescents," Pediatric Anesthesia, Vol. 18, No. 2, 2008, pp. 11901195.

[11] R. N. Soliman, A. R. Hassan, A. M. Rashwan and A. M. Omar, "Prospective, Randomized Study to Assess the Role of Dexmedetomidine in Patients with Supratentorial Tumors Undergoing Craniotomy under General Anaesthesia," Middle East Journal of Anesthesiology, Vol. 21, No. 3, 2011, pp. 325-334.

[12] M. Schoeler, P. D. Loetscher, R. Rossaint, A. V. Fahlenkamp, G. Eberhardt, S. Rex, J. Weis and M. Coburn, "Dexmedetomidine Is Neuroprotective in an in Vitro Model for Traumatic Brain Injury," BMC Neurology, Vol. 12, 2012, p. 20. http://dx.doi.org/10.1186/1471-2377-12-20

[13] S. Dahmani, D. Rouelle, P. Gressens and J. Mantz, "Characterization of the Postconditioning Effect of Dexmedetomidine in Mouse Organotypic Hippocampal Slice Cultures Exposed to Oxygen and Glucose Deprivation," Anesthesiology, Vol. 112, No. 2, 2010, pp. 373-383. http://dx.doi.org/10.1097/ALN.0b013e3181ca6982

[14] K. Engelhard, C. Werner, E. Eberspacher, M. Bachl, M. Blobner, E. Hildt, P. Hutzler and E. Kochs, "The Effect of the Alpha 2-Agonist Dexmedetomidine and the n-Methyld-Aspartate Antagonist $\mathrm{s}(+)$-Ketamine on the Expression of Apoptosis-Regulating Proteins after Incomplete Cerebral Ischemia and Reperfusion in Rats," Anesthesia \& Analgesia, Vol. 96, No. 2, 2003, pp. 524-531.

[15] R. N. Soliman, A. R. Hassan, A. M. Rashwan and A. M. Omar, "Prospective, Randomized Controlled Study to Assess the Role of Dexmedetomidine in Patients with Supratentorial Tumors Undergoing Craniotomy under General Anesthesia," Middle East Journal of Anesthesiology, 
Vol. 21, No. 1, 2011, pp. 23-33.

[16] R. K. Stoelting, "Blood Pressure and Heart Rate Changes during Short-Duration Laryngoscopy for Tracheal Intubation: Influence of Viscous or Intravenous Lidocaine," Anesthesia \& Analgesia, Vol. 57, No. 2, 1978, pp. 197199. http://dx.doi.org/10.1213/00000539-197803000-00009

[17] R. A. Allberry and H. F. Drake, "Preoperative BetaBlockade for Patients Undergoing Craniotomy: A Comparison between Propranolol and Atenolol," Canadian Journal of Anaesthesia, Vol. 37, No. 4, 1990, pp. 448-451. http://dx.doi.org/10.1007/BF03005625

[18] W. S. Kang, S. Y. Kim, J. C. Son, J. D. Kim, H. B. Muhammad, S. H. Kim, T. G. Yoon and T. Y. Kim, "The Effect of Dexmedetomidine on the Adjuvant Propofol Requirement and Intraoperative Hemodynamics during Remifentanil-Based Anesthesia," Korean Journal of Anesthesiology, Vol. 62, No. 2, 2012, pp. 113-118. http://dx.doi.org/10.4097/kjae.2012.62.2.113

[19] Z. Ozkose, F. S. Demir, K. Pampal and S. Yardim, "Hemodynamic and Anesthetic Advantages of Dexmedetomidine, an Alpha 2-Agonist, for Surgery in Prone Position," Tohoku Journal of Experimental Medicine, Vol. 210, No. 2, 2006, pp. 153-160. http://dx.doi.org/10.1620/tjem.210.153

[20] S. R. Arain and T. J. Ebert, "The Efficacy, Side Effects, and Recovery Characteristics of Dexmedetomidine versus Propofol When Used for Intraoperative Sedation," Anesthesia \& Analgesia, Vol. 95, No. 2, 2002, pp. 461-466.

[21] R. Y. Klinger, W. D. White, B. Hale, A. S. Habib and E. Bennett-Guerrero, "Hemodynamic Impact of Dexmedetomidine Administration in 15,656 Noncardiac Surgical Cases," Journal of Clinical Anesthesia, Vol. 24, No. 3, 2012, pp. 212-220. http://dx.doi.org/10.1016/j.jclinane.2011.07.016

[22] M. Shukry and J. A. Miller, "Update on Dexmedetomidine: Use in Nonintubated Patients Requiring Sedation for Surgical Procedures," Therapeutics and Clinical Risk Management, Vol. 6, 2010, pp. 111-121. http://dx.doi.org/10.2147/TCRM.S5374

[23] A. Bekker, M. Sturaitis, M. Bloom, M. Moric, J. Golfinos, E. Parker, R. Babu and A. Pitti, "The Effect of Dexmedetomidine on Perioperative Hemodynamics in Patients Undergoing Craniotomy," Anesthesia \& Analgesia, Vol. 107, No. 4, 2008, pp. 1340-1347. http://dx.doi.org/10.1213/ane.0b013e3181804298

[24] M. A. Mirski, Lewin Jr., S. Ledroux, C. Thompson, P. Murakami, E. K. Zink and M. Griswold, "Cognitive Improvement during Continuous Sedation in Critically Ill, Awake and Responsive Patients: The Acute Neurological ICU Sedation Trial (Anist)," Intensive Care Medicine, Vol. 36, No. 9, 2010, pp. 1505-1513. http://dx.doi.org/10.1007/s00134-010-1874-9

[25] A. Bekker and M. K. Sturaitis, "Dexmedetomidine for Neurological Surgery," Neurosurgery, Vol. 57, No. 1,
2005, pp. 1-10.

http://dx.doi.org/10.1227/01.NEU.0000163476.42034.A1

[26] M. Cosar, O. Eser, H. Fidan, O. Sahin, S. Buyukbas, Y. Ela, M. Yagmurca and O. A. Ozen, "The Neuroprotective Effect of Dexmedetomidine in the Hippocampus of Rabbits after Subarachnoid Hemorrhage," Surgical Neurology, Vol. 71, No. 1, 2009, pp. 54-59. http://dx.doi.org/10.1016/j.surneu.2007.08.020

[27] J. C. Drummond, A. V. Dao, D. M. Roth, C. R. Cheng, B. I. Atwater, A. Minokadeh, L. C. Pasco and P. M. Patel, "Effect of Dexmedetomidine on Cerebral Blood Flow Velocity, Cerebral Metabolic Rate, and Carbon Dioxide Response in Normal Humans," Anesthesiology, Vol. 108, No. 2, 2008, pp. 225-232. http://dx.doi.org/10.1097/01.anes.0000299576.00302.4c

[28] A. S. Uyar, H. Yagmurdur, Y. Fidan, C. Topkaya and H. Basar, "Dexmedetomidine Attenuates the Hemodynamic and Neuroendocrinal Responses to Skull-Pin Head-Holder Application during Craniotomy," Journal of Neurosurgical Anesthesiology, Vol. 20, No. 3, 2008, pp. 174-179. http://dx.doi.org/10.1097/ANA.0b013e318177e5eb

[29] I. Rozet, "Anesthesia for Functional Neurosurgery: The Role of Dexmedetomidine," Current Opinion in Anaesthesiology, Vol. 21, No. 5, 2008, pp. 537-543. http://dx.doi.org/10.1097/ACO.0b013e32830edafd

[30] P. O. Talke and M. Maze, "Expecting the Unexpected," Anesthesia \& Analgesia, Vol. 106, No. 6, 2008, pp. 16051606. http://dx.doi.org/10.1213/ane.0b013e31816c3f69

[31] M. Venn, J. Newman and M. Grounds, "A Phase II Study to Evaluate the Efficacy of Dexmedetomidine for Sedation in the Medical Intensive Care Unit," Intensive Care Medicine, Vol. 29, No. 2, 2003, pp. 201-207.

[32] J. D. Tobias, J. W. Berkenbosch and P. Russo, "Additional Experience with Dexmedetomidine in Pediatric Patients," Southern Medical Journal, Vol. 96, No. 9, 2003, pp. 871-875. http://dx.doi.org/10.1097/01.SMJ.0000053557.75799.09

[33] J. D. Tobias and J. W. Berkenbosch, "Sedation during Mechanical Ventilation in Infants and Children: Dexmedetomidine versus Midazolam," Southern Medical Journal, Vol. 97, No. 5, 2004, pp. 451-455. http://dx.doi.org/10.1097/00007611-200405000-00007

[34] K. P. Mason, D. Zurakowski, S. E. Zgleszewski, C. D. Robson, M. Carrier, P. R. Hickey and J. A. Dinardo, "High Dose Dexmedetomidine as the Sole Sedative for Pediatric MRI," Pediatric Anesthesia, Vol. 18, No. 5, 2008, pp. 403-411. http://dx.doi.org/10.1111/j.1460-9592.2008.02468.x

[35] K. P. Mason, S. Zgleszewski, R. E. Forman, C. Stark and J. A. DiNardo, "An Exaggerated Hypertensive Response to Glycopyrrolate Therapy for Bradycardia Associated with High-Dose Dexmedetomidine," Anesthesia \& Analgesia, Vol. 108, No. 3, 2009, pp. 906-908. http://dx.doi.org/10.1213/ane.0b013e3181948a6f 